\title{
The Invisible Hand Plays Dice: Multiple Equilibria in Sects Markets
}

\author{
Panu Poutvaara \\ University of Helsinki and HECER \\ and \\ Andreas Wagener \\ University of Hannover
}

Discussion Paper No. 282

November 2009

ISSN 1795-0562

HECER - Helsinki Center of Economic Research, P.O. Box 17 (Arkadiankatu 7), FI-00014 University of Helsinki, FINLAND, Tel +358-9-191-28780, Fax +358-9-191-28781, E-mail info-hecer@helsinki.fi, Internet www.hecer.fi 


\title{
The Invisible Hand Plays Dice: Multiple Equilibria in Sects Markets*
}

\begin{abstract}
Religious participation is much more widespread in the United States than in Europe, while Europeans tend to view sects more suspiciously than Americans. We propose an explanation for these patterns without assuming differences in preferences or market fundamentals. We study a religious market where both demand and supply of spiritual services are endogenous. Such markets may have multiple equilibria. Further, equilibria with more sects result in higher welfare and lower membership costs, as secular societies tend to host on average more demanding sects.
\end{abstract}

JEL Classification: Z12, L89, J24, D71.

Keywords: Sects, religion, sects markets.

Panu Poutvaara

Department of Economics

P.O. Box 17

University of Helsinki

00014 University of Helsinki

FINLAND

panu.poutvaara@helsinki.fi
Andreas Wagener

University of Hannover

Institute of Social Policy

Koenigsworther Platz 1

30167 Hannover

GERMANY

wagener@sopo.uni.hannover.de

* We thank Vikas Kumar, Mikael Priks, conference participants in Berlin, three anonymous referees and the Editor in Chief, William F. Shughart II, for their useful comments. 


\section{Introduction}

Religious attitudes and participation differ markedly between the United States and Europe. In the United States, more than $40 \%$ of population attend church weekly and religious participation has increased steadily over the last two hundred years. Europe is much more secular: In Denmark, Finland, Norway and Sweden, less than $10 \%$ of population attend church weekly, in the United Kingdom around 15\%, and in Germany 16\% (Iannaccone 1998; Bruce 1999; GESIS 2008: 19). Starting from higher levels of religiosity, Catholic European countries like Italy, Ireland, Portugal, and Spain have experienced remarkably strong trends towards secularization; the same applies to Orthodox Greece (Brañas-Garza 2004; Voas 2004).

Also political attitudes and public opinion towards the necessity or desirability of policing religious groups tend to differ significantly between Europe and the United States (Kent 2001). In general, Europeans have a more cautious attitude towards new religious groups while Americans place higher value on religious laissez-faire. Several European governments engage in the regulation and surveillance of sects (e.g., Scientology), and France in 2001 even adopted a law (known as Loi About-Picard) with the intention of repressing and controlling cultic movements that undermine human rights and fundamental freedoms. Such regulations are alleged by many commentators (notably from the United States) to infringe religious and civic freedoms (Hervieu-Léger 2004).

So far, the economic theory of religion has been divided over possible causes of the great differences in religious participation and attitudes towards sects. The dominant strand of the theory of religious markets, the so-called supply-side theory, views the demand for religion as largely invariant across time and space such that differences in religious patterns must be attributed to differences on the supply sides of religious markets (Stark and Bainbridge 1996; Stark and Finke 2001). Supply-side theory argues that 
religious markets in Europe are dominated by "lazy" monopoly churches without entrepreneurial zeal while the United States hosts large numbers of competitive sects and religious groups that vie actively for devotees. Openness and competitive pressures in American religious markets serve the needs of religious customers better and thereby generate higher participation and consumer satisfaction than drowsy religious dinosaurs in Europe. Studies by Iannaccone (1991), Stark and Iannaccone (1994), Stark et al. (1995), and Iannaccone (1998) indeed corroborate a positive correlation between rates of religious diversity and religious participation. However, Voas et al. (2002) and Bruce (1999) dismiss these observations as mere statistical artefacts. Moreover, supply-side theory so far has not been able to resolve a number of intriguing puzzles in religious markets. It, for example, cannot explain why more fervent sects do not overtake "monopoly churches" in Western Europe where religious competition has been free for at least several decades. Furthermore, supply-side theory has trouble with explaining why there are also vast differences in religious market structures across the United States - although the same openness and rights of religious freedom apply in all states. ${ }^{1}$ In addition, Bruce (1999: Chs. 3 and 4) and Chaves and Gorsky (2001) cite numerous examples from the United States and Europe, both historical and recent, suggesting that the supply siders' prediction of a positive association between pluralism and religious vitality is questionable. Finally, supply-side theory cannot (and, to be fair, does not try to) explain why attitudes towards the regulation of religious markets differ so greatly across countries that are equally strict in their separation of church and state like the United States and France. ${ }^{2}$

In this paper, we propose a formal model of a sects market from which

\footnotetext{
${ }^{1}$ Also see Bruce (1999) on that point. For empirical evidence on differences in religious participation within the United States, see adherents.com (2009).

${ }^{2}$ According to Chaves and Cann (1992) and Messner (1999), the United States, Canada, Australia, France, the Netherlands and, surprisingly, Ireland are the Western countries where religion is most deregulated and church-state separation is strictest.
} 
a possible story for these phenomena emerges. In that model, both demand and supply are endogenous: Customers (i.e., potential members of sects) have religious wants. Entrepreneurs in the sects market provide spiritual services and, in return, demand compensation that depends on their personal characteristics, which we label as "persuasiveness". ${ }^{3}$ More persuasive leaders are able to collect larger contributions and thus have a comparative advantage in running a sect. ${ }^{4}$ As in many contributions to the economics of religion (for an exception see, however, Azzi and Ehrenberg 1975), our paper focuses on life on earth, without taking a stance on the existence of afterlife. The potential benefits of an afterlife are taken as a given intrinsic motivation for sect membership.

Our analysis provides a possible way of obtaining cross-country differences in religious outcomes without resorting to differences in religious demand or supply as such. This argument is based on a multiplicity issue: equilibria in sects markets are generally not unique. In particular, both "secular" (European-type) equilibria - characterized by a small number of small sects demanding large contributions of their members and an otherwise low religious participation rate - and "sectarian" (American-type) equilibria where a substantial part of the population is distributed over a large number of on average rather low-demanding sects - might emerge. The same set of initial conditions (represented by distributions of consumer preferences and the characteristics of the suppliers of religious services) might give rise to different outcomes with respect to religious participation in the population,

\footnotetext{
${ }^{3}$ Viewing religious groups as driven by monetary incentives dates at least back to Adam Smith (1999[1776]: 376f). Empirical evidence ranges from the medieval Catholic church (see, e.g., Ekelund et al. 1989, 2006: Ch. 5), the Protestant reformation (Ekelund et al. $2002)$ to U.S. "televangelist" Jim Bakker who diverted money collected from his followers to pay for private luxuries, including an air-conditioned dog-kennel. See Iannaccone (1998), Iannaccone and Berman (2006), or Ekelund et al. (2006: Ch. 2) for surveys on entrepreneurial models of religious groups.

${ }^{4}$ Whether the question is of a congregation belonging to a larger denomination, a church, a sect or a cult, we refer to those groups simply as "sects", and we use the word in a neutral sense.
} 
the number of active sects in the market, the extent of their activities, and their membership costs.

The underlying feature of sects markets which potentially results in multiple equilibria is - in our model - a complementarity between demand and supply: when more people are willing to join a sect, less persuasive sect leaders enter the market, which reduces average membership costs; and the lower are the average membership costs in sects, the more individuals are willing to join a sect.

A further implication of this complementarity in our model is that the smaller is the number of sects that are active in a market equilibrium the higher are the demands which these sects impose on their (relatively few) members. ${ }^{5}$ That is, in more secular societies sects impose, on average, heavier burdens on their small membership groups than in societies with higher rates of religious participation. Hence, fears that sect leaders might "abusively" extract significant resources from their members would then seem, on average, more justified in a secular than in a sectarian equilibrium. Different religious equilibria might therefore also frame the perception of sects and, as a consequence, policy attitudes towards them.

While essentially relying on a demand-and-supply framework, our analysis entails some features that make it particularly relevant for discussing religious markets even without explicit reference to doctrinal issues: the importance attached to personal characteristics of leaders; asymmetric information upon entrance in a group; the significance of psychic exit costs; the absence of legal obligations for members to pay for membership services consumed; the absence of an obligation for leaders to reveal the price they aim to charge before members enter; and the payment of membership contributions only after

\footnotetext{
${ }^{5}$ We only consider monetary contributions (tithes). Apart from asking for money, religious groups can and do require much of their members (Iannaccone 1992b, Berman 2000). They impose significant costs in terms of sacrifice, abstinence from certain pleasures, strict morality and even stigma upon their members and, in the extreme, may even drive them to martyrdom.
} 
getting involved with the group. Due to its simplicity, our model necessarily is incomplete. While we establish the possibility of multiple equilibria, we touch only briefly on the issue of equilibrium selection. As in other areas of economics that encounter multiple equilibria, equilibrium selection could be determined by initial conditions. This would then allow one to incorporate many of the aspects of a country's history, demographics, politics, or economic circumstances that we omit. For the moment we simply point to the possibility of multiplicity rather than positing a (necessarily quite specific) model for resolving this indeterminacy.

We should stress that we do not deny that there exist substantial differences in religious markets between the United States and Europe, e.g., with respect to regulation, scrutiny of religion, or monopolization. Neither do we reject the view that differences in religious behavior across the U.S. might indeed be caused by different attitudes and preferences in religious and non-religious matters. We claim only that it is not necessary to rely on such differences in the "fundamentals" in order to obtain a theoretical explanation for differences in the outcomes of sects markets. ${ }^{6}$

While our paper endogenizes both supply and demand of religious activities, the theory of religious markets has so far focused mainly on the supply side (for a thorough recent survey, see Kumar 2008). The four exceptions we are aware of set up Hotelling-type models of religious markets: Rodero and Brañas (2000) analyze price competition among religious suppliers, assuming denominational positions in the religious spectrum as exogenously given. In McBride (2008a,b), ex ante identical religious groups choose their positions in the religious market such as to maximize their share of adherents, thereby establishing groups differing in their religious strictness. Potential members differ in their preferences. In our framework, potential religious entrepreneurs and potential members both are ex ante different. Entrepre-

\footnotetext{
${ }^{6}$ In other words, the supply-sider's tenet that "[f]aced with American-style churches, Europeans would respond as Americans do" (Stark and Finke 2000: 237f) needs to be qualified with the addition "provided that religious markets possess a unique equilibrium".
} 
neurs differ in their personal characteristics, and potential members in their valuation of spiritual services. Information is asymmetric: members cannot observe the type of the sect's leader before entering, even though they have rational expectations of the distribution of potential types. Due to asymmetric information, sect members may end up being asked to make more sacrifices than they would have been willing to make ex ante. ${ }^{7}$ Finally, Barro and McCleary (2005) take the Hotelling model as their starting point for an empirical analysis of which countries have state religions.

Any notion of sects markets is only meaningful when there is freedom to join or to leave religious groups (and possibly, on the supply side, to establish new groups). Countries or time periods where religious freedoms are heavily constrained are, thus, beyond the scope of our analysis. This excludes great parts of today's Muslim world. Compared to Western countries, religious diversity is typically limited and religious participation more obligatory in Islamic countries. Moreover, it seems generally problematic to transfer the standard theological or sociological concepts of "sects" one-by-one to Islam (Sedgwick, 2001). Yet, as is argued, e.g., in Sedgwick (2007) or Iannaccone and Berman (2006), the socio-economic mechanisms of religious groups generally also apply to the various denominations and (radical) sects of Islam. Indeed, Chaves et al. (1994) demonstrate that predictions from the supplyside theory of religion also seem to be empirically valid in case of Islam, at least in European countries: Muslim religious activities (measured by Hajj participation) are higher for Muslims in religiously more liberal countries than in more regulated countries.

Our paper is organized as follows. In Section 2, we present a stylized model of a sects market. Section 3 analyzes equilibria in the religious econ-

\footnotetext{
${ }^{7}$ For example, it is unlikely that many of the more than 900 members who committed suicide or were killed in Jonestown in Guyana in 1978 could have anticipated such a level of sacrifice when they entered Jim Jones's sect called People's Temple. Also accusations of sexual abuse and financial extortion suggest that the leaders' type was not perfectly known to members before they entered. On the positive side, sects that outsiders fear to be abusive may turn out to be benevolent in their members' experience.
} 
omy and their properties (comparative statics, existence, uniqueness, welfare). Section 4 interprets our observations. Section 5 summarizes our findings and concludes. All proofs are in the Appendix.

\section{A model of sects markets}

\subsection{General description}

In an economy, there exist two types of agents: (potential) sect leaders and (potential) sect members. We assume that the mass of potential members and of potential leaders both are equal to one.

Sect leaders own sects that offer spiritual services, social contacts, and other intangible benefits exclusively ${ }^{8}$ for their customers. Sect leaders differ from one another in their leadership qualities, and sect members are distinguished by their willingness-to-pay for the services provided by sects. Sect leaders are interested in expected profits, sect members search to maximize expected lifetime utility.

A (free-entry) equilibrium in the sects market in this economy requires three components: (i) sect foundations are consistent with profit-maximizing behavior of potential sect leaders; (ii) a matching of potential sect members to the active sects must be compatible with utility maximization of sect members and profit maximization of sect leaders; and (iii) new entry into the sect market cannot be profitable.

\subsection{Potential sect leaders}

In the beginning each potential sect leader decides whether to establish a new sect, or to stay outside the market. In the latter case, he will receive

\footnotetext{
${ }^{8}$ This club-good feature of religious benefits has been stressed, e.g., by Ekelund et al. (2006: Ch. 2).
} 
a deterministic reservation profit which we normalize to zero. Establishing a new sect comes at a fixed set-up cost $d>0$, consisting of the costs of constructing a doctrine, recruiting first disciples, and opening a church or temple. The set-up cost is net of any psychological or spiritual satisfaction that a sect leader might gain from establishing or taking over a sect. There is no need, thus, to explicitly consider the religious motivations of sect leaders. Sect leaders earn their revenues by charging contributions from their members, but only at the end of the period, i.e., after having attracted the members to their sect (see below).

Potential sect leaders differ in their "persuasiveness". We use that word as a simple and generic term for all attributes of a sect leader that make membership in his sect attractive and exit more costly for potential adherents: personal charm, negotiating skills, telegenic appearance, sermonic fervor, and convincingness. ${ }^{9}$

Persuasiveness determines how much the sect leader can request from sect members. Unlike for other social groups, the ability of sect leaders to charge contributions from members does not derive from a binding contract, signed upon entrance into the sect, but from associating exit or expulsion from the sect with certain religious or social costs (after-life punishment, loss of the social network etc.) that sect members wish to avoid. For believers, a threat of afterlife punishment is credible; individuals unwilling to adhere to the sect's rules and discipline risk the wrath of God, damnation, or other sanctions in the afterlife.

At the time of establishing the sect and of attracting members, persuasiveness is the leader's private knowledge but it is non-verifiable. The persuasiveness of potential sect leaders is distributed with continuous density $f(p)$

\footnotetext{
${ }^{9}$ There is a link between persuasiveness in our model and the notion of "charisma" in the tradition of Max Weber. According to Weber (1978[1922]: 241), "charisma" refers "to a certain quality of an individual personality by virtue of which he is considered extraordinary and treated as endowed with supernatural, superhuman, or at least specifically exceptional powers or qualities. (...) [O]n the basis of them [i.e., these qualities] the individual concerned is treated as a 'leader'".
} 
over a closed interval $[0, \bar{p}]$. By $F(p)$ we denote the attending cumulative distribution function. ${ }^{10}$

We do not presume anything about the religious qualities of sects or their doctrines. All what matters is the persuasiveness of sect leaders, which is an inherently personal characteristic.

\subsection{Potential sect members}

There is a continuum of consumers who consider joining a sect. Each individual is assumed to enter at most one sect. ${ }^{11}$ If an individual stays out of any sect, (s)he will receive a reservation utility, normalized to zero. If an individual enters the sect, (s)he establishes social contacts with other members, as well as receiving religious benefits and services. By experience, individuals learn the persuasiveness of their sect leaders. At the end of the membership period, sect leaders ask sect members to contribute money or services. In each sect, all members pay the same contribution while contributions differ across sects. ${ }^{12}$ Sect members then choose whether to pay what is asked or to exit the sect. When indifferent, they stay.

\footnotetext{
${ }^{10}$ As argued by a referee, persuasiveness might be an ordinal variable; our analysis and especially the algebraic operations below seem to suggest that we use it cardinally. However, the mathematics would also work (with a bit more notational complexity) for general functional relationships. What we essentially require is that leaving a sect with a more persuasive leader causes higher exit costs and, thus, enables the sect leader to charge higher contributions.

${ }^{11}$ This is in line with the empirical observation that multiple affiliations to religious groups play only a subordinate role, given the often exclusive nature and clear demarcation of most systems of belief (Haug 2001). Japan, where many people say they are both Buddhists and Shintoists and where statistics for religious membership add up to almost 200\% of the population, seems to be an exception. As explained by Stark (2004: 157) this may be due to an understanding of "religious affiliation" that differs from Europe and the United States.

${ }^{12}$ The role of uncertainty and commitment costs in selecting a sect is also stressed by Bold and Hull (1998) in a model of religious varieties. Assuming uniform contributions within a sect does not detract from the model's generality. At the cost of some notational complexity, we could assume that potential sect members differ in income and in the shares of incomes they are willing to give to the sect leader of a given persuasiveness.
} 
We denote by $h$ the individual's willingness to pay for the religious benefits and services associated with becoming a sect member and assume that $h$ is distributed across the population with density $g(h)$ and support $[\underline{h}, \bar{h}]$. Correspondingly, denote by $G(h):=\int_{\underline{h}}^{h} g(\xi) d \xi$ the cumulative distribution function of $h$.

The utility $u$ of type- $h$ consumer if (s)he enters a sect whose leader has persuasiveness $p$ is given by

$$
u(h, c)= \begin{cases}h-\tau(p) & \text { if he stays in the sect and pays contributions } \\ h-x(p) & \text { if he leaves the sect }\end{cases}
$$

where $\tau$ and $x$ denote contributions (tithes) and exit costs, respectively.

In (1) we assume that the religious gross benefits of sect membership (establishing a relationship with God, obtaining ethical guidelines, being baptized etc.) are irredeemable, i.e., they would not be lost upon exit from the sect. Religious net benefits in case of leaving the sect may differ, as a persuasive sect leader may convince sect members of after-life punishment if they leave (also see footnote 13 below). This also reflects the typical time pattern of sect membership: members first receive services without paying and become absorbed, and only later are they asked to pay. Therefore, our model suggests that religious organizations may allow people to participate without contributing until they become absorbed. What may appear as tolerating free-riding by new members can then, effectively, be a profit-maximizing investment into making them stay.

In reality, entrance choices into sects are driven not only by expectations about the sect leader's persuasiveness but also by past experiences, family and ethnic backgrounds, or social environments. For sake of simplification, we omit these issues; they do not affect the core of our argument.

In (1) it is further assumed that neither contributions nor exit costs differ across individuals. The first assumption can be justified by the inability of sects effectively to differentiate the contributions they levy according to 
their members' individual willingness to pay, which is private information. The second assumption is made for simplicity. If the willingness to pay for sect membership depended on an individual-specific variable and sect leader's persuasiveness, then sect leaders would ask for a contribution so as to maximize expected payments from their members, taking into account that this may lead into exit by those with the lowest willingness to pay.

We assume that exit costs $x$ are strictly increasingly related to the persuasiveness level of the sect leader. For simplicity, but without any loss of generality, we will henceforth assume that exit costs are (numerically) equal to the persuasiveness level of the sect leaders from whose sect the members exit: $x(p)=p$.

Upon entrance into a sect, the leader's persuasiveness is still unknown to potential sect members. Hence, all sects appear ex ante identical and membership decisions are based on expectations about membership and exit costs (taking into account that these are related one-to-one to persuasiveness levels).

\section{Equilibria and their properties}

\subsection{Equilibrium in the sects market}

Knowing the preference structure of his members, a profit-maximizing sect leader will demand contributions equal to what would be his members' 
exit cost. That is, contributions (numerically) equal persuasiveness: ${ }^{13}$

$$
\tau(p)=x(p)=p
$$

As a consequence of this price setting, no sect member will ever leave a sect. Denoting by $P$ the expected persuasiveness level in the religious market, consumer $h$ expects his or her utility (1) from joining a sect to be equal to

$$
E u(h, p)=h-P .
$$

While each individual treats $P$ as exogenous, it is endogenous on the level of economy.

With a reservation utility of zero, an individual of type $h$ will join a sect whenever $h \geq P$. If an individual of type $h$ joins a sect, so will all individuals of types $h^{\prime}>h$ (at a given level of $P$ ). Denote by $\widehat{h}$ the smallest willingnessto-pay that leads to sect-membership. The mass of individuals who join a sect at all is then given by $1-G(\widehat{h})$.

A sect leader with persuasiveness level $p$ expects to earn profits

$$
m \cdot p-d
$$

Here, $m$ denotes the number of members per-sect.

A sect leader's profits increase with his persuasiveness. Thus, if a sect leader with persuasiveness $p$ becomes active (i.e., (3) is non-negative), so will all more persuasive leaders. In a long-run equilibrium of the sects market, profitable entry does no longer occur. Hence, the marginal persuasiveness

\footnotetext{
${ }^{13}$ We could easily add to the model benefits from sect membership that positively depend on the persuasiveness of the sect leader and that would be foregone upon exit from the sect. Denoting such benefits by $b(p)$, individual $h$ 's utility (1) from becoming and staying a sect member would then be $h+b(p)-\tau(p)$, while the decision to first join and later leave a sect would yield $h-x(p)$. Profit-maximizing sect leaders then would never charge their sect members in excess of $\tau(p)=x(p)+b(p)$ which is strictly increasing in $p$ and would, therefore, result in an equivalent specification of our model.
} 
level, denoted as $\widehat{p}$, at which a sect leader would enter the sects market emerges from equating (3) to zero:

$$
\widehat{p}=\frac{d}{m}
$$

The mass of sects that are active in the sects market is then given by $1-F(\widehat{p})$.

For potential sect members the expected costs of sect membership are determined by the lower bound of persuasiveness in the market:

$$
P=P(\widehat{p}):=E(p \mid p \geq \widehat{p})=\frac{1}{1-F(\widehat{p})} \int_{\widehat{p}}^{\bar{p}} p f(p) \mathrm{d} p .
$$

As sect leaders' persuasiveness is private knowledge, sect members who wish to enter a sect are equally distributed among all active sects. Hence, the per-sect mass of members is given by

$$
m=\frac{1-G(\widehat{h})}{1-F(\widehat{p})} .
$$

An equilibrium in the sects market is, thus, characterized by a pair $(\widehat{h}, \widehat{p})$ satisfying

$$
\begin{aligned}
\alpha(\widehat{h}, \widehat{p}) & =P(\widehat{p})-\widehat{h}=0 \\
\beta(\widehat{h}, \widehat{p}) & =d-\frac{1-G(\widehat{h})}{1-F(\widehat{p})} \cdot \widehat{p}=0 .
\end{aligned}
$$

The loci $\alpha=0$ and $\beta=0$ can be interpreted as, respectively, the demand and the (long-run) supply function of the sects market. Both loci describe upward-sloped graphs in the $(\widehat{h}, \widehat{p})$-space. To see this, first observe from $(5)$ that expected membership costs are higher, the higher are persuasiveness requirements to induce sect leaders to enter into the market:

$$
P^{\prime}(\widehat{p})=\frac{f(\widehat{p})}{1-F(\widehat{p})} \cdot[P(\widehat{p})-\widehat{p}]>0
$$


The positive slopes of $\alpha=0$ and $\beta=0$ then follow from

$$
\begin{aligned}
& \alpha_{p}(\widehat{h}, \widehat{p})=P^{\prime}(\widehat{p})>0 \\
& \alpha_{h}(\widehat{h}, \widehat{p})=-1 \\
& \beta_{p}(\widehat{h}, \widehat{p})=-\frac{1-G(\widehat{h})}{(1-F(\widehat{p}))^{2}} \cdot(1-F(\widehat{p})+\widehat{p} f(\widehat{p}))<0 \\
& \beta_{h}(\widehat{h}, \widehat{p})=g(\widehat{h}) \cdot \frac{\widehat{p}}{1-F(\widehat{p})}>0 .
\end{aligned}
$$

Intuitively, this makes sense: Consumers' threshold willingness to pay for joining a sect rises with the expected membership costs which themselves increase in the level of persuasiveness (hence, the $\alpha$-locus is upward-sloped). On the other hand, the threshold level for sect leaders to enter into the sects market decreases with market size (since all costs are fixed costs) which itself is smaller the fewer customers join a sect (hence, the $\beta$-locus is also upwardsloped).

\subsection{Comparative statics}

Assume that $h$ and $p$ are distributed such that an equilibrium (i.e., a simultaneous solution of $\alpha=\beta=0$ ) exists. We directly obtain from (6) and (7) that $\widehat{p}$ and $\widehat{h}$ move in identical directions as $d$ : if set-up costs increase, fewer sects ( $\widehat{p}$ increases) go along with higher membership costs and, thus, fewer sect members $(\widehat{h}$ increases, too). To summarize:

Proposition 1 A (small) increase in the set-up costs for sects leads to less activities in the sects market if and only if the initial equilibrium in the sects market exhibits Marshallian stability.

Geometrically, an increase in the costs of establishing a sect leads to fewer activities (fewer sects and fewer sect members) if and only if the "demand curve" (i.e., $\alpha(h, p)=0$ understood as the amount of persuasiveness $p$ that 
would be demanded if the price were $h$ ) is flatter than the "supply curve" (i.e., $\beta(h, p)=0$ understood as the amount of persuasiveness $p$ that would be supplied if it earned a price $h$ ). While this condition generally cannot be ensured, Marshallian stability of equilibria in the sects market is intuitively plausible, as the adjustment process underlying this stability concept makes clear: Suppose the sects market is out of equilibrium and, say, offered positive profits to some potential sect leaders who are currently inactive (the case of losses to marginal active sects follows mutatis mutandis). In particular, those potential sect leaders who previously were indifferent whether to enter or not now would find it optimal to enter the market. In turn, the average price of sect membership would decrease which would encourage more potential members to join a sect. This would attract even more entrants, and the upward spiral in the number of sects and in sect membership would continue until a new equilibrium is reached.

\subsection{Existence and multiplicity of equilibria}

So far, we have taken for granted both the existence and the uniqueness of an equilibrium in the sects market. However, as both $\alpha=0$ and $\beta=0$ are upward-sloped, neither non-existence nor multiplicity of equilibria can be ruled out.

Clearly, the equilibrium configurations are determined by the primitives of the model - which in our case are the distribution functions (including the support) of consumer types and persuasiveness levels. Depending on their shape, equilibria may fail to be unique or even to exist. This point can be easily made for the case of uniform distributions. In particular, observe

Proposition 2 Suppose that the distribution of persuasiveness across sect leaders is uniform on the interval $[0,1]$ and the distribution of consumer types is uniform on $[a, b]$, where $0 \leq a<1 .{ }^{14}$ Then there exists $\bar{b} \in(a, 1)$

\footnotetext{
${ }^{14}$ The case $a \geq 1$ is uninteresting as everybody would then join a sect for sure.
} 
such that:

- If the maximal willingness to pay for sect membership is too low (i.e., if $b<\bar{b})$, then no equilibrium exists in sects markets.

- If the maximal willingness to pay for sect membership is below, but not too much so, the maximal persuasiveness level (i.e., if $1 \geq b>\bar{b}$ ), then two equilibria exist in the sects market.

- If the maximal willingness to pay for sect membership exceeds the maximal persuasiveness level (i.e., if $b>1$ ), a unique equilibrium exists in the sects market.

Figure 1 illustrates this proposition for $d=0.25$ and consumer types distributed uniformly on $[0.5, b]$, where we chose $b$ to take values of $0.7,0.82$, $0.9,1$, and 1.1 .

Figure 1 goes here.

In Figure 1, (6) is represented by the straight line. In increasing order of $b$ from left to right, the convex curves show condition (7). In line with Proposition 2 , the number of equilibria develops from zero $(b=0.7)$ to one $(b=0.82)$ to two $(b=0.9$ and $b=1)$, back to one again $(b=1.1)$. The exact equilibrium values of $\widehat{h}$ and $\widehat{p}$ are calculated in the Appendix.

The possible multiplicity of equilibria in sects markets can be explained as follows: Before entering a sect, individuals form expectations about the costs of sect membership. An individual will become a member of a sect if his willingness to pay for sect services exceeds or equals expected membership costs. These costs are, however, on average lower the larger is the number of sects that is active in the market. Looking at the supply side of the market, however, sects will enter the market only if they can at least recover their costs from membership contributions. This condition is easier to be met the larger the sect or the more persuasive the sect leader (since he can extract 
higher contributions); both effects point in the direction of a small number of active sects. As a consequence, the equilibrium configuration is not clear.

In essence, multiplicity is caused by a complementarity between demand (represented by $\widehat{h}$ ) and supply (represented by $\widehat{p})$ : the more people are willing to join a sect, the lower is the minimum persuasiveness level needed to attract them; and the lower the persuasiveness level (i.e., the cheaper sect membership), the more individuals are willing to join a sect.

With multiple equilibria, those with higher persuasiveness thresholds (and, thus, with fewer sects) also exhibit higher willingness-to-pay thresholds (and, thus, lower religious participation). Hence, there can be

- equilibria with many sects, a high rate of sect membership in the population and rather low expected membership costs (as low-profile sect leaders with low persuasiveness also enter the market); and

- equilibria with a small number of sects, a low rate of membership but rather high expected membership costs (as only high-profile sect leaders enter the market).

We call the former type of equilibria sectarian and the latter type secular. In the uniform case reported in Proposition 2, multiplicity comes in the form of one sectarian and one secular equilibrium. However, with non-uniform distributions multiplicity generally is not limited to two equilibria only; the loci (6) and (7) may intersect many times. Using a piecewise uniform distribution for persuasiveness, we provide an example for the (up to) four-equilibria case; adding more segments with different densities to the distribution would then allow us to generate as many equilibria as we wish.

\subsection{Dynamic stability}

The existence of several equilibria raises the issue of which equilibrium will actually emerge. Typically (and especially in macroeconomics, where 
models with multiple equilibria abound), ${ }^{15}$ this question is approached by a stability analysis in a dynamic framework. Following these examples, we suggest a simple version of Marshallian dynamics for the sects market:

$$
\begin{aligned}
& \left.\dot{h}(h, p)=s_{1} \cdot(P(p)-h)\right) \\
& \dot{p}(h, p)=s_{2} \cdot\left(d-\frac{1-G(h)}{1-F(p)} \cdot p\right)
\end{aligned}
$$

where $s_{1}, s_{2}>0$ denote adjustment speeds. The first equation states that demand for sect membership will increase (i.e., $h$ will decrease) if joining a sect is utility-increasing (see (2)). The second equation implies that there will be market entry of additional sect leaders (i.e., $p$ will decrease) if the sects market still offers positive profits (see (3)). A market equilibrium $(\widehat{h}, \widehat{p})$ clearly will be a steady-state $(\dot{h}=\dot{p}=0)$ of these markets dynamics. The stability properties are summarized in

Proposition 3 A steady state of the system (8) and (9) is asymptotically stable whenever the market equilibrium exhibits Marshallian stability.

Together with Proposition 1, this result states that every equilibrium configuration that shows reasonable comparative static properties (in the sense that higher costs lead to reduced religious activities) can also be reached as the long-run outcome of a dynamic process with entry and exit of sect leaders and sect members.

For multiple equilibria with uniform distributions, Proposition 3 yields

Corollary 4 Suppose that sect leaders' persuasiveness and consumers' willingnessto-pay are uniformly distributed. If there are multiple (in this case, two) equilibria in the sects market, then the sectarian one is (asymptotically) stable while the secular one is unstable.

\footnotetext{
${ }^{15}$ See, e.g., Howitt and McAfee (1988), or Graham and Temple (2006).
} 
We should stress that this corollary does not imply that secular equilibria are unlikely to persist: The corollary holds only for uniform distributions; for other distributions, situations with low religious participation can well be stable.

\section{5 "Excessive" membership fees}

Finally, let us hint at an interesting feature of equilibria in the sects market:

Proposition 5 Membership fees in some sects may exceed the maximum willingness to pay of every sect member.

An example for this feature is provided in the proof of Proposition 2 (see the "sectarian cases" for $b<1$ there). The point is relevant for sects whose leaders are very persuasive. Membership in such sects entirely consists of ex post-disappointed individuals. Ex ante, however, these individuals joined sects voluntarily, engaging in a gamble with expected positive payoff.

\subsection{Welfare comparison}

While establishing welfare comparisons between various equilibria is, in general, a demanding task, our model allows for a simple and clear-cut ranking of equilibria in the sects market. We obtain

Proposition 6 When there are multiple equilibria, they can be ranked so that the more active sects there are in an equilibrium, the higher are consumer surplus and producer surplus, and the lower is the average price of sect membership.

As both consumer surplus and producer surplus are larger with more sects, so is social welfare. Our finding suggests that currently active sect 
leaders could benefit from increased competition by new entrants. As increased competition by less persuasive sect leaders results in lower average membership costs, it encourages entry by potential members staying initially outside the market.

Furthermore, we find that entry by less effective sect leaders requires an increase in average sect size $(1-F(\widehat{p})) /(1-G(\widehat{h}))$, thus boosting the profits of more effective sect leaders. A market-creating effect, i.e., the increase in overall religious participation $1-G(\widehat{h})$ would then override a market-stealing effect, triggered by the increase in the number of suppliers $1-F(\widehat{p})$.

\section{Interpretation}

Our sparse model suggests possible explanations for differences in the religious participation in Europe and in the United States. While these explanations are somewhat speculative and we do not claim to say a final word on the topic, we hope that our framework provides inspiration for future studies.

\subsection{Multiple equilibria}

Our first contribution is to demonstrate that countries, although being (nearly) identical with respect to their current conditions for religious demand and supply can end up in different equilibrium configurations of their sects markets. As shown in the previous section, the same set of demand and supply parameters may lead into secular (low level of religious activities) and sectarian (high level) equilibria. From an interpretative view, the presence of two equilibria with the same underlying distribution suggests that different equilibria in the sects market need not reflect fundamental differences in populations, but may simply result from different contingencies. The structure of the market of religions does not necessarily bear a one-to-one relation to the distribution of religious traits, spiritual desires, or social needs in a 
population.

Cross-country differences in sects market equilibria need, thus, not be due to differences in supply or demand conditions, different degrees of informational asymmetries, different institutional settings, differences in the populations' spiritual neediness or susceptibility to religious marketing etc.; they simply could be different equilibrium realizations in a market game with indeterminate outcome.

Our model does not rule out the possibility that there exist several asymptotically stable equilibria in sects markets (see the example in the Appendix). In a dynamic context each of these equilibria could actually be observable under occasional perturbations of the system. This observation could strengthen the contingency interpretation of differences in sects market outcomes: Even countries (say, within continental Europe or different US states) that started from historically similar situations with respect to religious regulations, population structures, etc. could, over time, be driven to entirely dissimilar religious outcomes that may persist even after the initial differences no longer are present. An analysis of the underlying historical reasons for the different equilibria is an important challenge for future research, possibly jointly with historians.

As is the case with many models where multiple equilibria are Pareto rankable, there is no guarantee that society does not get stuck in a dominated equilibrium. This is, e.g., the case in Keynesian macro-models of thin markets à la Diamond (1982) or Howitt (1985). Coordination failure (with the result that dominated equilibria are played) is quite commonly also observed in reality and in experiments.

Finally, recall that when fewer people join sects, higher expected membership costs are imposed on those who join. The more secular a society the more demanding are those few sects that actually are active - and the more easily can these sects be regarded as exploiting or abusing their members. This observation might explain why attitudes towards sects are less lenient 
in "secular" countries than when larger fractions of the population are religiously affiliated.

\subsection{Welfare results}

Proposition 6 states that sectarian equilibria generate higher welfare than secular equilibria (which host more demanding sects). A lower average persuasiveness - and, thus, lower expected membership costs and a larger number of sects - are welcomed by consumers (individual and total expected consumer surplus increase), and by sect leaders (the incumbents benefit from increased sect sizes and the new entrants would otherwise stay out of the market).

An important caveat with respect to our welfare results is that they refer to ordinary sects that charge a membership fee as an ex-post compensation for providing religious services. In an amplified manner, the same mechanism can also be exploited by destructive [religious] sects and even terrorist groups. At worst, such groups end up promoting violence against other people or suicide of their members (think, e.g., of al-Qaida, Aum Shinri Kyo, or the Davidian Branch). Berman (2003), Ferrero (2005), and Iannaccone and Berman (2006) explain the emergence of radical religious militias and Jihadists along these lines.

As outlined at the end of Section 3.5., finding oneself trapped in a highly demanding sect might be the unwarranted consequence of a rational gamble. Those not believing that people choose faith or sect affiliations in a rational way may see members of such high-demanding ("abusive") sects as victims who ought to be protected by the state. Different views on individual rationality then translate into different policy stands: a laissez-faire policy concerning religion is more consistent with the assumption of full rationality, while a more interventionist policy would draw support from imperfect rationality. 


\section{Concluding remarks}

In this paper, we make several contributions to the economic theory of religion: First, we offer an explanation, consistent with rational choices of sect members and of religious entrepreneurs, for the puzzlingly large differences in religious market outcomes and membership across the United States or between the United States and most European countries. By showing that sects markets may exhibit multiplicity, we complement (and partly challenge) the so-called supply-side theory of religious markets according to which different patterns of religious activities in different countries are mainly the consequence of different supplies in the religious market. ${ }^{16}$ The observation that a single set of initial (demand and supply) conditions can give rise to a multitude of equilibrium outcomes with high or low rates of religious participation, larger or smaller sects, and higher or lower average costs of sect membership suggests that the observed diversity in religious patterns might just be an eventuality.

Second, we augment the theory of religious markets by considering free entry decisions of potential sect leaders. So far, the supply side in religious market (the set of active religious entrepreneurs) has by and large been assumed to be parametrically fixed. We view endogenizing entry into the religious market to be crucial in understanding the religious market in countries without state-endowed monopoly churches and possibly also in countries with such a monopoly; see Barro and McCleary (2005).

Third, we demonstrate that membership in an "abusive" and exploiting sect need not be an irrational act. Wishing never to have entered a certain

\footnotetext{
${ }^{16}$ While Bruce (1999) uses evidence that contradicts the supply-side theory of religious markets to dismiss the rational-choice approach to religion, our analysis suggests that the rational-choice approach is well-suited to derive a manifold of empirically relevant predictions, and therefore ought to be refined, rather than dismissed, as a tool for analyzing religion.
} 
sect can just be the undesired consequence of an ex-ante perfectly rational gamble.

A fourth contribution consists of welfare analysis. We establish conditions under which an equilibrium with a larger number of sects results in higher consumer and producer surpluses. We even find that a move to an equilibrium with more active sects is accompanied by an increase in average sect size and in sect profits. The market-creating effects of sectarian competition exceed the market-stealing effects. However, these results only hold under the restrictive assumptions of the model, including that religious groups do not generate any externalities and that membership in such groups is an individual choice.

Fifth, we tentatively relate our findings to the emergence of political attitudes concerning the necessity of policing sects markets. We demonstrate that in more secular societies (say, the European ones) sects impose, on average, heavier burdens on their members than in societies with higher rates of religious participation (say, the United States). Fears that sect leaders might (abusively) extract significant resources and control the private lives of their members would then appear, on average, more justified in a secular than in a sectarian equilibrium. Differences in the perception of sects, therefore, need not reflect differences in underlying preferences or market basics, but may already arise from living in societies with different equilibria. 


\section{Appendices}

Proof of Proposition 1

From (6) and (7) we derive:

$$
\frac{\mathrm{d} \widehat{p}}{\mathrm{~d} d}=\left[\beta_{p}(\widehat{h}, \widehat{p})+\beta_{h}(\widehat{h}, \widehat{p}) \cdot P^{\prime}(\widehat{p})\right]^{-1} .
$$

The sign of (10) is a priori unclear. Observe, however, that

$$
\begin{aligned}
\frac{\mathrm{d} \widehat{p}}{\mathrm{~d} d} \geq 0 \quad & \Longleftrightarrow \quad \frac{\beta_{p}(\widehat{h}, \widehat{p})}{\beta_{h}(\widehat{h}, \widehat{p})} \leq \frac{\alpha_{p}(\widehat{h}, \widehat{p})}{\alpha_{h}(\widehat{h}, \widehat{p})} \\
& \left.\Longleftrightarrow \quad \frac{\mathrm{d} \widehat{p}}{\mathrm{~d} \widehat{h}}\right|_{\beta=0} \geq\left.\frac{\mathrm{d} \widehat{p}}{\mathrm{~d} \widehat{h}}\right|_{\alpha=0} .
\end{aligned}
$$

This is precisely the condition for Marshallian stability (Takayama 1985: 296f). Observe that it can be written as

$$
f(\widehat{p}) g(\widehat{h}) \widehat{p}(P(\widehat{p})-\widehat{p}) \geq(1-G(\widehat{h}))(1-F(\widehat{p})+\widehat{p} f(\widehat{p})) .
$$

Both sides of this inequality are positive, but cannot generally be compared. QED

\section{Proof of Proposition 2}

Assume that the distributions of persuasiveness across sect leaders and of consumer types are both uniform. That is, $h$ is uniformly distributed over an interval $[a, b] \subset R$ with $b>a>0$, and $p$ is uniformly distributed on $[0,1]$, which is an innocuous normalization. ${ }^{17}$ The sects market is then

\footnotetext{
${ }^{17}$ If $p$ were uniformly distributed over $\left[\gamma_{1}, \gamma_{2}\right]$, define $\widetilde{p}:=\left(p-\gamma_{1}\right) /\left(\gamma_{2}-\gamma_{1}\right)$ which will be uniform on $[0,1]$. Then let $h$ undergo the same shift; this would not affect uniformity of its distribution. Proceed as below and afterwards re-transform the variables.
} 
characterized by

$$
P(\widehat{p})=\frac{1+\widehat{p}}{2}, \quad \text { and } \quad m=\frac{b-\frac{1+\widehat{p}}{2}}{b-a} .
$$

Hence (6) reads as

$$
\widehat{p}=2 \widehat{h}-1=: p_{1}(\widehat{h})
$$

while (7) is given by $\frac{b-\widehat{h}}{b-a} \cdot \frac{\widehat{p}}{1-\widehat{p}}=d$ or

$$
\widehat{p}=\frac{d(b-a)}{d(b-a)+b-\widehat{h}}=: p_{2}(\widehat{h}) .
$$

While $p_{1}$ establishes a positively linear relationship between $\widehat{p}$ and $\widehat{h}, p_{2}$ is an increasing and strictly convex function of $\widehat{h}$. Hence, there can at most be two points of intersection of $p_{1}$ and $p_{2}$.

Observe that $\partial p_{2}(\widehat{h}) / \partial b \geq 0$ if and only if $\widehat{h} \geq a$ - which always holds. Hence, in the relevant range, an increase of $b$ shifts $p_{2}(\widehat{h})$ rightwards.

Now suppose $b=1$. We then have two equilibria: a corner equilibrium $(\widehat{h}, \widehat{p})=(1,1)$ and an interior equilibrium at $(\widehat{h}, \widehat{p})=(0.5+(1-a) d, 2(1-a) d)$.

Increasing $b$ above 1 makes the corner equilibrium disappear (recall that $p_{2}$ will shift to the right such that the new intersection with $p_{1}$ would require $\widehat{p}>1$ - which is infeasible). The interior equilibrium will remain as the unique equilibrium.

Decreasing $b$ below 1 will keep the two equilibria, which will move together the further we lower $b$. Consider

$$
\bar{b}:=\frac{1}{2(1+d)^{2}} \cdot\left[1+(3+2 a) d+2 a d^{2}+2 \sqrt{d(1+2 d-2 a(1+d))}\right] .
$$

At $\bar{b}$ we get that at equilibrium (i.e., when $p_{1}(\widehat{h})=p_{2}(\widehat{h})$ ), function $p_{2}$ is tangent to $p_{1}$, i.e., $p_{2}^{\prime}(\widehat{h})=2=p_{1}^{\prime}(\widehat{h})$. Hence, we get a unique equilibrium, and lowering $b$ below $\bar{b}$ makes equilibria disappear entirely. Below we list 
equilibrium configurations for $d=0.25$ and $a=0.5$ (from which $\bar{b}=0.82$ ):

\begin{tabular}{c|l}
$b$ & Equilibria $(\widehat{h}, \widehat{p})$ \\
\hline 1.1 & $(0.619,0.237)$ \\
1.0 & $(0.625,0.25),(1,1)$ \\
0.9 & $(0.638,0.276),(0.862,0.723)$ \\
$\bar{b}=0.82$ & $(0.7,0.4)$ \\
$<0.82$ & none. \\
\hline
\end{tabular}

A graphical illustration is provided in Figure 1 (main body of the text). Suppose, e.g., that $b=0.9$. Then, the second equilibrium is of the secular type: only a small fraction of the population (4\%) is member of a sect, paying a high price (and active sect leaders' persuasiveness levels are high). The first equilibrium is sectarian with a large number of sects of rather low average persuasiveness; a large share (more than 70\%) of the population is enrolled in sects, at relatively low average costs.

QED

\section{Examples with more than two equilibria}

We now show that the number of equilibria in the sects market can exceed two. As in the proof of Proposition 2, assume that persuasiveness $p$ is uniformly distributed on $[0,1]$. As a consequence, (6) again reads as $\widehat{h}=(1+\widehat{p}) / 2$ or

$$
\widehat{p}=2 \widehat{h}-1=: p_{1}(\widehat{h}) .
$$

By variation, assume that $h$ is piecewise uniformly distributed on a positive interval $[a, b]$ in the following way $\left(a \leq a_{1} \leq a_{2} \leq b\right.$ with at least one strict 
inequality, and $\gamma>0$ suitably ${ }^{18}$ chosen):

$$
g(h)=\left\{\begin{array}{cc}
\gamma & a \leq h<a_{1} \\
\frac{1-\gamma\left(b-a_{2}+a_{1}-a\right)}{a_{2}-a_{1}} & a_{1} \leq h \leq a_{2} \\
\gamma & a_{2}<h \leq b
\end{array}\right.
$$

and $g(h)=0$ for $h \notin[a, b]$. (For $a=a_{1}$ and $b=a_{2}$, this boils down to the scenario in the proof of Proposition 2, independently of $\gamma$.) The distribution function $G(h)=\int_{a}^{h} g(\xi) \mathrm{d} \xi$ is, thus, piecewise linear on $[a, b]$, with kinks at $a_{1}$ and $a_{2}$. Then (7) is given by

$$
\widehat{p}=\frac{d}{d+1-G(\widehat{h})}=: p_{2}(\widehat{h})
$$

and an equilibrium is given through a value $\widehat{h}$ such that $p_{1}(\widehat{h})=p_{2}(\widehat{h})$.

Set $d=0.25, a=0.5$ (as in the proof of Proposition 2) and $b=1$. Independently of $a_{1}, a_{2}$ and $\gamma$, there will always be an (unstable) fully secular equilibrium without any sect activities: $\widehat{h}=\widehat{p}=1 .{ }^{19}$ Now fix $a_{1}=0.55$ and $a_{2}=0.75$ and let $\gamma$ vary. ${ }^{20}$

Figure 2 goes here.

Figure 2 depicts $p_{1}(\widehat{h})$ (the straight line) and $p_{2}(\widehat{h})$ for $\gamma=0.25,0.75,1$, and 2 (in descending order of the kinked curves). The number of equilibria varies from 1 to 4 to 3 to 2 . Labelling, in the four-equilibria case $(\gamma=0.75)$, the two equilibria with high participation rates "sectarian" and the other two "secular", we observe that one sectarian and one secular equilibrium are stable, while the other two equilibria are not.

Now set $b=1.2$ (all other parameters unchanged). Then the fully secular equilibrium disappears, and all equilibria are interior. Figure 3 depicts $p_{1}(\widehat{h})$

\footnotetext{
18 "Suitably" means that $g(h) \geq 0$ for $a_{1} \leq h \leq a_{2}$. This condition will always be satisfied in the numerical examples.

${ }^{19}$ As $G(1)=1$, we get that $p_{2}(1)=1$. Moreover, $p_{1}(1)=1$. Hence, an equilibrium.

${ }^{20}$ Mathematica files for the calculations and graphs are available on request.
} 
(the straight line) and $p_{2}(\widehat{h})$ for $\gamma$-values of $1,0.6$, and 0.2 (in descending order of the kinked curves), all exhibiting different stability patterns: For $\gamma=1$, there is a unique stable secular equilibrium, while for $\gamma=0.2$, there is a unique sectarian equilibrium. For $\gamma=0.6$, there are one stable sectarian equilibrium, one stable secular equilibrium, and an unstable intermediate one.

Figure 3 goes here.

By adding more kinks to the distribution of $h$, we can generate scenarios with an arbitrary number of equilibria in the sects market. Moreover, also stability patterns may vary considerably. As our examples illustrate, both high- and low-participation equilibria can be stable also in the case of multiple equilibria.

\section{Proof of Proposition 3}

A steady state $(\widehat{h}, \widehat{p})$ of the first-order system of differential equations (8) and (9) is asymptotically stable if each eigenvalue of the Jacobian matrix of the system is negative or has negative real part. It is unstable, if at least one eigenvalue is positive or has positive real part. The Jacobian of (8) and (9) is

$$
M=\left(\begin{array}{cc}
\alpha_{h}(\widehat{h}, \widehat{p}) & \alpha_{p}(\widehat{h}, \widehat{p}) \\
\beta_{h}(\widehat{h}, \widehat{p}) & \beta_{p}(\widehat{h}, \widehat{p})
\end{array}\right)
$$

where the entries are given in Section 3.1. Its eigenvalues are

$$
e_{1,2}=\frac{T}{2} \pm \sqrt{-D+\frac{T^{2}}{4}}
$$

where $T$ and $D$ are the trace and the determinant of $M$. Observe that $T=\alpha_{h}+\beta_{p}<0$. Hence, $D>0$ is sufficient and necessary for $(\widehat{h}, \widehat{p})$ to be asymptotically stable: If $D>T^{2} / 4>0$, then the root in (12) will be imaginary but the real part of the eigenvalues will be negative. If $0<D \leq$ 
$T^{2} / 4$, the root in (12) will be real, but in absolute value smaller than $|T / 2|$; hence both eigenvalues are negative. If $D<0$, the root in (12) will be real, but in absolute value larger than $|T / 2|$; hence one positive and one negative eigenvalue emerge.

Finally, note that $D=\alpha_{h}(\widehat{h}, \widehat{p}) \cdot \beta_{p}(\widehat{h}, \widehat{p})-\alpha_{p}(\widehat{h}, \widehat{p}) \cdot \beta_{h}(\widehat{h}, \widehat{p})>0$ is the condition for Marshallian stability, known already from the proof of Proposition 1.

QED

\section{Proof of Corollary 1}

Recall from the proof of Proposition 2 that a steady state (geometrically) emerges in the intersection of a strictly convex and increasing function $\left(p_{2}\right.$, representing $\beta$ ) with a linear function $\left(p_{1}\right.$, representing $\alpha$ ). With multiplicity, the slope of $p_{2}$ in steady states with smaller [higher] participation rates must be smaller [larger] than that of $p_{1}$. However, $p_{2}^{\prime}=-\beta_{h} / \beta_{p}$ and $p_{1}^{\prime}=-\alpha_{h} / \alpha_{p}$ such that $p_{2}^{\prime}<[>] p_{1}^{\prime}$ is tantamount to $D>[<] 0$. Now apply Proposition $3 .^{21}$ QED

\section{Proof of Proposition 6}

Consider two alternative equilibria, called $\varphi_{1}$ and $\varphi_{2}$, such that the number of sects is larger in $\varphi_{2}: \widehat{p}_{1}>\widehat{p}_{2}$. From (5), the expected membership cost is decreasing in the number of active sect leaders: $P\left(\widehat{p}_{2}\right)<P\left(\widehat{p}_{1}\right)$. Thus, individuals who are sect members in $\varphi_{1}$ can receive services by sects at a lower price in $\varphi_{2}$. These individuals will therefore be sect members in $\varphi_{2}$, too, and will enjoy a higher consumer surplus then. Moreover, overall participation will be higher in $\varphi_{2}$ than in $\varphi_{1}: \widehat{h}_{2}<\widehat{h}_{1}$. The additional sect members receive non-negative expected surplus in $\varphi_{2}$, compared to zero in $\varphi_{1}$. Hence, consumer surplus is higher in $\varphi_{2}$ than in $\varphi_{1}$.

\footnotetext{
${ }^{21}$ The claim can also be verified algebraically. For uniform distributions, it turns out that in a steady state with $p$-value $\widehat{p}, D=(1-2 b-\widehat{p}(2-\widehat{p})) /\left(2(b-a)(1-\widehat{p})^{2}\right)$ which is positive when the numerator is. Plugging in the values for $\widehat{p}$ and investigating the sign leads to the desired results.
} 
When $\widehat{p}$ decreases, equality in (7) can only be maintained if average sect size $(1-F(\widehat{p})) /(1-G(\widehat{h}))$ increases. Producer surplus of those sects active in $\varphi_{1}$ is then larger in $\varphi_{2}$, as they receive the same contribution per member from a larger group of members. Additional sects in $\varphi_{2}$ only enter if they earn non-negative profits, implying that producer surplus in $\varphi_{2}$ is larger than in $\varphi_{1}$.

QED

\section{References}

adherents.com (2009). http://www.adherents.com. Accessed November 14, 2009.

Azzi, C., \& Ehrenberg, R. (1975). Household allocation of time and church attendance. Journal of Political Economy 83, 27-56.

Barro, R. J. \& McCleary, R. M. (2005). Which countries have state religions? Quarterly Journal of Economics 120, 1331-1370.

Barros, P. P. \& Garoupa, N. (2002). An economic theory of church strictness. The Economic Journal 112, 559-576.

Baumol, W. J. \& Bowen, W. G.(1966). Performing Arts: The Economic Dilemma. New York: Twentieth Century Fund.

Berman, E. (2000). Sect, subsidy, and sacrifice: an economist's view of ultra-orthodox Jews. Quarterly Journal of Economics 115, 905-953.

Berman, E. (2003). Hamas, Taliban and the Jewish underground: an economist's view of radical religious militias. NBER Working Paper 10004, National Bureau of Economic Research, Cambridge.

Bold, F. \& Hull, B.B. (1998). Product variety in religious markets. Review of Social Economy 56, 1-19. 
Brañas-Garza, P. (2004). Church attendance in Spain (1930-1992). Gender differences and secularization. Economics Bulletin 26, 1-9.

Bruce, S. (1999). Choice and Religion. A Critique of Rational Choice Theory. Oxford: Oxford University Press.

Chaves, M. (2006). All creatures great and small: megachurches in context. Review of Religious Research 47, 329-346.

Chaves, M. \& Cann, D.E. (1992). Regulation, pluralism, and religious market structure. Explaining religion's vitality. Rationality and Society 4, 272-290.

Chaves, M. \& Gorsky, P.S. (2001). Religious pluralism and religious participation. Annual Review of Sociology 27, 261-281.

Chaves, M., Schraeder, P.J., \& Sprindys, M. (1994). State regulation of religion and Muslim religious vitality in the industrialized West. Journal of Politics 56, 1087-1097.

Dahl, G.B., \& Ransom, M.R. (1999). Does where you stand depend on where you sit? Tithing donations and self-serving beliefs. American Economic Review 89, 703-727.

Diamond, P.A. (1982). Aggregate demand management in search equilibrium. Journal of Political Economy 90, 881-894.

Ekelund, R.B., Hébert, R.F., \& Tollison, R.D. (1989). An economic model of the medieval church: usury as a form of rent seeking. Journal of Law, Economics and Organization 5, 307-331.

Ekelund, R.B., Hébert, R.F., \& Tollison, R.D. (2002). An economic analysis of the Protestant Reformation. Journal of Political Economy 110, 646671. 
Ekelund, R.B., Hébert, R.F., \& Tollison, R.D. (2006). The marketplace of Christianity. Cambridge: The MIT Press.

Ferrero, M. (2005). Radicalization as a reaction to failure: an economic model of Islamic extremism. Public Choice 122, 199-220.

GESIS - German Social Science Infrastructure Services e.V. (2008). The German system of social indicators. Available at http://www.gesis . org/ fileadmin/upload/dienstleistung/daten/soz_indikatoren/SSI_en/ 10_par_tab.pdf. November 14, 2009.

Graham, B. \& Temple, J. (2006). Rich nations, poor nations: how much can multiple equilibria explain? Journal of Economic Growth 11, 5-41.

Haug, W. (2001). Ethnic, religious and language groups: towards a set of rules for data collection and statistical analysis. International Statistical Review 69, 303-311.

Hervieu-Léger, D. (2004). France's obsession with the "sectarian threat". In: Lucas, P.C. \& Robbins, T. (eds.), New religious movements in the twenty-first century: legal, political, and social challenges in global perspective. London: Routledge, pp. 49-60.

Howitt, P. (1985). Transaction costs in the theory of unemployment. American Economic Review 75, 88-100.

Howitt, P., \& McAfee, R.P. (1988). Stability of equilibria with externalities. Quarterly Journal of Economics 103, 261-277.

Iannaccone, L.R. (1991). The consequences of religious market structures: Adam Smith and the economics of religion. Rationality and Society 3, 156-177.

Iannaccone, L.R. (1992a). Religious markets and the economics of religion. Social Compass 39, 123-131. 
Iannaccone, L.R. (1992b). Sacrifice and stigma: reducing free-riding in cults, communes, and other collectives. Journal of Political Economy 100, 271-291.

Iannaccone, L.R. (1998). Introduction to the Economics of Religion. Journal of Economic Literature 36, 1465-1496.

Iannaccone, L.R., \& Berman, E. (2006). Religious extremism: the good, the bad, and the deadly. Public Choice 128, 109-129.

Kent, S.A. (2001). The French and German versus American debate over 'New Religions', Scientology, and human rights. Marburg Journal of Religion 6, 1-13.

Kumar, V. (2008). A critical review of economic analyses of religion. SSRN Working Paper. Available at http://ssrn. com/abstract $=1193862$. Accessed November 14, 2009.

McBride, M. (2008a). Religious pluralism and religious participation: a game theoretic analysis. American Journal of Sociology 114, 77-108.

McBride, M. (2008b). Religious market competition in a richer world. Forthcoming, Economica.

Messner, F. (1999). La législation cultuelle des pays de l'Union Européenne face aux groupes sectaires. In: Champion, F. \& Cohen, M. (eds.), Sectes et Démocratie. Paris: Editions du Seuil, pp. 331-358.

Rodero, J. \& Brañas, P. (2000). Hotelling and the Olympus: modelling differences in religious prices. Central European Journal of Operations Research 8, 265-283.

Sedgwick, M. (2000). Sects in the Islamic world. Nova Religio 3, 195-240.

Sedgwick, M. (2007). Jihad, modernity, and sectarianism. Nova Religio 11, 6-27. 
Smith, A. (1999) [1776]. The Wealth of Nations. Books IV-V. London: Penguin Classics.

Stark, R. (2004). Exploring the Religious Life. Baltimore: Johns Hopkins University Press.

Stark, R., \& Bainbridge, W.S. (1996). A Theory of Religion. New Brunswick: Rutgers University Press.

Stark, R. \& Finke, R. (2000). Acts of Faith. Explaining the Human Side of Religion. Berkeley: University of California Press.

Stark, R., Finke, R., \& Iannaccone, L.R. (1995). Pluralism and piety: England and Wales, 1851. Journal for the Scientific Study of Religion $34,431-444$.

Stark, R. \& Iannaccone, L.R. (1994). A supply-side reinterpretation of the "secularization" of Europe. Journal for the Scientific Study of Religion $33,230-252$.

Takayama, A. (1985). Mathematical economics. 2nd edition, Cambridge: Cambridge University Press.

Voas, D. (2004). Religion in Europe. One theme, many variations? Mimeo, University of Manchester.

Voas, D., Olsen, D.V.A., \& Crockett, A. (2002). Religious pluralism and participation: why previous research is wrong. American Sociological Review 67, 212-230.

Weber, M. (1978) [1922], Economy and society. An outline of interpretive sociology. Berkeley etc.: University of California Press. 


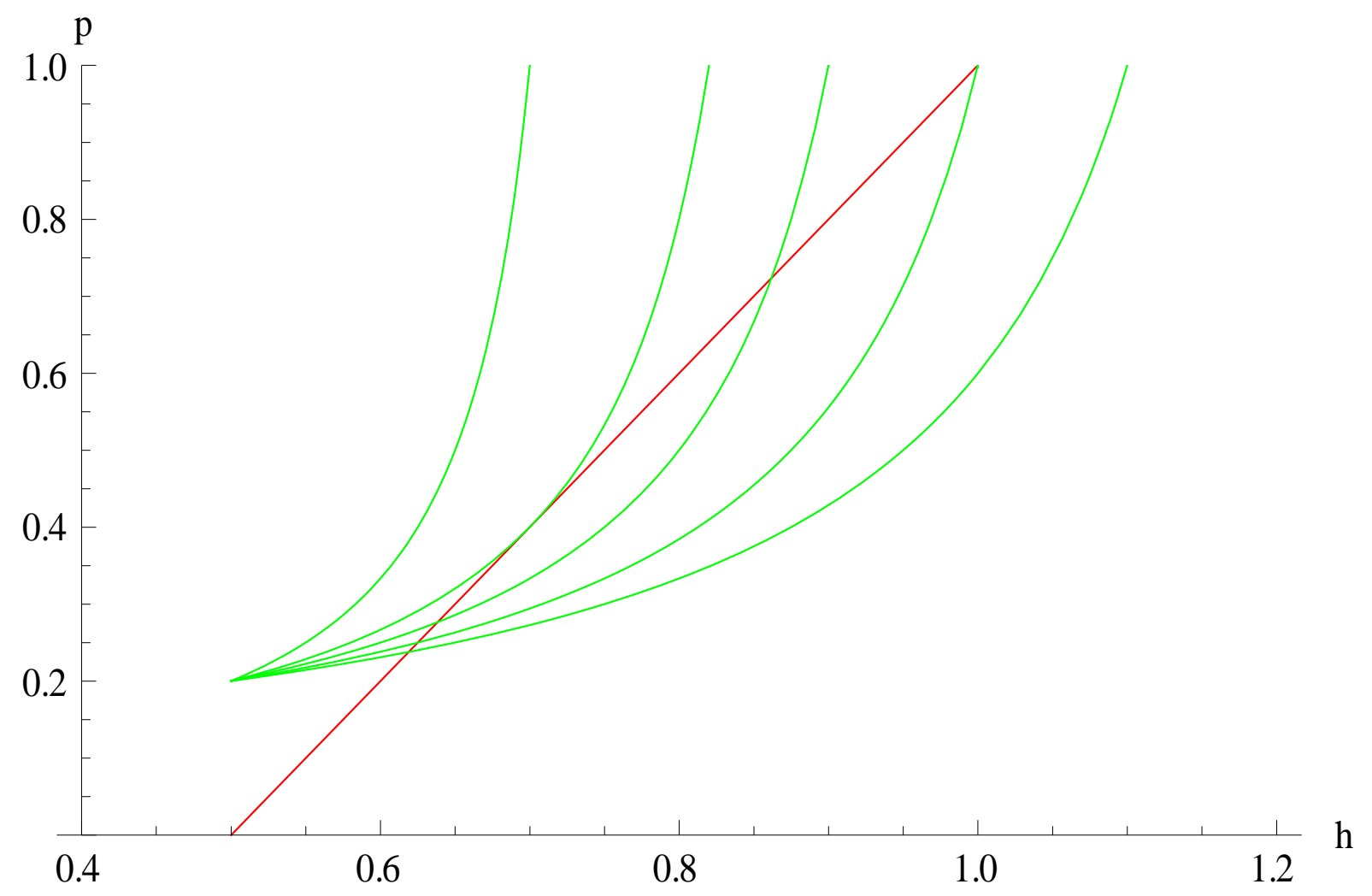

Figure 1: Equilibria with uniform distributions 




Figure 2: Multiple equilibria with piecewise uniform distributions ( $b=1$ ) 




Figure 3: Multiple equilibria with piecewise uniform distributions ( $b=1.2)$ 